\title{
Agôn
}

Revue des arts de la scène

Critiques | Saison 2011-2012

\section{Histoires de trajectoires}

La Loi du marcheur, de et par Nicolas Bouchaud, mise en scène Eric Didry

\section{Caroline Châtelet}

\section{Q OpenEdition}

Journals

Édition électronique

URL : http://journals.openedition.org/agon/2186

DOI : 10.4000/agon.2186

ISSN : 1961-8581

Éditeur

Association Agôn

Référence électronique

Caroline Châtelet, « Histoires de trajectoires », Agôn [En ligne], Critiques, mis en ligne le 02 février 2012, consulté le 23 septembre 2020. URL : http://journals.openedition.org/agon/2186 ; DOI : https:// doi.org/10.4000/agon.2186

Ce document a été généré automatiquement le 23 septembre 2020

Association Agôn et les auteurs des articles 


\title{
Histoires de trajectoires
}

La Loi du marcheur, de et par Nicolas Bouchaud, mise en scène Eric Didry

\author{
Caroline Châtelet
}

\section{NOTE DE L'ÉDITEUR}

Article paru dans le numéro 18 de la revue Novo.

1 Avec La Loi du marcheur, le comédien Nicolas Bouchaud transmet la parole de Serge Daney dans une forme stimulante, qui invite à un dialogue avec le cinéma et ses œuvres.

Dans son ouvrage Éloge de la marche, l'anthropologue et sociologue David Le Breton raconte à travers des expériences et des exemples littéraires la richesse que procure ce mode de déplacement. "Propice au développement d'une philosophie élémentaire de l'existence ", la marche instaure un rapport spécifique au temps et au monde. Difficile de savoir si Serge Daney, mort en 1992 du sida, connaissait les écrits de David Le Breton... Toujours est-il que c'est pour définir le lien que l'homme entretenait à son métier de critique et au cinéma que l'historien Jean Douchet parla de «loi du marcheur ». Une expression à son tour reprise par Nicolas Bouchaud pour porter au théâtre la parole de Daney. Ainsi, dans La Loi du marcheur, Bouchaud - instigateur et interprète du projet - et Eric Didry - metteur en scène - partent d'Itinéraire d'un cinéfils, entretien filmé entre Daney et Régis Debray. Pour autant, il ne s'agit pas d'une lecture et Bouchaud et Didry réalisent un véritable geste de théâtre en s'emparant de ce dialogue. D'abord par le dispositif scénographique, écran accueillant des extraits du film Rio Bravo, et dont le désaxement fait déborder la toile sur le sol. Ou comment cette intrusion du cinéma sur la scène raconte avec justesse la porosité existant chez Daney entre le cinéma, la pensée critique et la vie. Tout en soulignant par ce franchissement symbolique de "la rampe ", espace défini par Daney comme "la ligne de fracture » séparant l'écran de la salle, l'incursion du cinéma au théâtre, voire, du théâtre au cinéma... Ensuite, il y a l'interprétation de Nicolas Bouchaud. Comédien à l'amplitude de jeu indubitable - parfois un brin cabot -, Bouchaud fait corps avec la parole du 
critique et la transmet dans une adresse directe. Cette conservation du caractère d'oralité ainsi que l'évacuation de la parole de Debray transforment les spectateurs en interlocuteurs de ce dialogue. Là où un théâtre illustratif ou mimétique figerait dans un hommage rigide la pensée du critique, la mise en scène révèle sa force, sa vivacité, et son élaboration. Comme le raconte Nicolas Bouchaud, «Serge Daney disait que ce que voir des films lui avait donné, c'était l'invention du temps. Inventer un temps à lui dans lequel il puisse vivre.» Cette découverte d'un temps à soi - qu'offre aussi la marche -, nous est communiquée par la double trajectoire du discours et de la mise en scène. Le temps commun de la représentation devient espace de partage et de dialogue avec le cinéma, avec ses œuvres, et avec ce qu'elles nous font. Mais ce que nous dit, aussi, en creux ce spectacle c'est la différence de temporalité - et donc nécessairement de rapport aux œuvres - séparant le théâtre du cinéma. Car là où au cinéma, il est possible d'évaluer ou réévaluer indéfiniment l'œuvre d'un réalisateur - de dialoguer avec les films dans le temps - au théâtre, hormis de très rares reprises, ce qui n'a pas été vu ne le sera jamais - ou alors en vidéo, mais ce n'est déjà plus du théâtre...

du 15 au 17 février 2012 au CDN de Sartrouville,

du 21 au 24 février 2012 à La Comédie de Reims,

les 1er et 2 mars 2012 à l'ABC de Bar-le-Duc,

du 6 au 10 mars 2012 au TNB de Rennes,

du 13 au 15 mars 2012 au TU de Nantes en collaboration avec le Grand T,

les 19 et 20 mars 2012 au Salmanazar d'Epernay,

les 23 et 24 mars 2012 à La Coursive de la Rochelle,

du 27 au 31 mars 2012 au Maillon - Le Wacken de Strasbourg

\section{INDEX}

Mots-clés : Bouchaud (Nicolas), Didry (Eric), La Loi du marcheur 